\title{
Anhedonia and substance dependence: clinical correlates and treatment options
}

\section{Daniele Stavros Hatzigiakoumis, Giovanni Martinotti*, Massimo Di Giannantonio and Luigi Janiri}

Istituto di Psichiatria e Psicologia, Università Cattolica del S. Cuore, Roma, Italy

\section{Edited by:}

Marco Diana, University of Sassari,

Italy

\section{Reviewed by:}

George Kenna, Brown University, USA

Marco Diana, University of Sassari,

Italy

\section{*Correspondence:}

Giovanni Martinotti, Clinica Villa Maria

Pia, Via del Forte Trionfale 36, 00135

Rome, Italy.

e-mail: giovanni.martinotti@gmail.com
Anhedonia is a condition in which the capacity of experiencing pleasure is totally or partially lost, and it refers to both a state symptom in various psychiatric disorders and a personality trait. It has a putative neural substrate, originating in the dopaminergic mesolimbic and mesocortical reward circuit. Anhedonia frequently occurs in mood disorders, as a negative symptom in schizophrenia, and in substance use disorders. In particular, we focus our attention on the relationships occurring between anhedonia and substance use disorders, as highlighted by many studies. Several authors suggested that anhedonia is an important factor involved in relapse as well as in the transition from recreational use to excessive drug intake. In particular, anhedonia has been found to be a frequent feature in alcoholics and addicted patients during acute and chronic withdrawal as well as in cocaine, stimulant, and cannabis abusers. Furthermore, in subjects with a substance dependence disorder, there is a significant correlation between anhedonia, craving, intensity of withdrawal symptoms, and psychosocial and personality characteristics. Therefore treating anhedonia in detoxified alcohol-dependent subjects could be critical in terms of relapse prevention strategies, given its strong relationship with craving.

Keywords: anhedonia, pleasure, dopaminergic reward system, SHAPS, CPAS, FCPS, substance use disorders
The word anhedonia was introduced in Psychiatry by Ribot (1896), who defined anhedonia as the inability to experience pleasure. Anhedonia refers to both a state symptom in various psychiatric disorders and a personality trait (Loas and Pierson, 1989).

A review of psychiatric textbooks in the late nineteenth century revealed that the loss of the pleasure response was recognized as an early and preeminent symptom of depression (Bucknill and Tuke, 1874; Clouston, 1896; Bevan, 1899). Anhedonia played an important role in psychopathology theories at the beginning of the twentieth century (Bleuler, 1911; Kraepelin, 1919; Myerson, 1923). In particular, Kraepelin (1919) spoke of anhedonia as a core symptom of a state of individual suffering, which was part of the dementia praecox. Bleuler (1911), noting the indifference that some patients showed toward their friends, acquaintances, colleagues, and at last life itself, defined anhedonia as a basic feature of their disease, "an external signal of their pathological condition."

Nevertheless later psychiatric interest in anhedonia faded; Jaspers (1913) in his "Allgemeine Psychopathologie. Ein Leitfaden für Studierende, Ärzte und Psychologen" does not mention anhedonia except as an aspect of the more severe and pervasive lost of all emotional response. Attention focused then on depressed mood as the pathognomonic feature of depressive illness. The International Classification of Diseases, 9th revision (ICD-9) does not mention anhedonia in its definition of the depressive phase of manic-depressive psychosis, but defines the disorder in terms of a "widespread depressed mood of gloom and wretchedness with some degree of anxiety" (World Health Organisation, 1978).

In the 1960s, interest in anhedonia rose again. Rado $(1956,1962)$ assigned anhedonia a more central role in the development of schizophrenia. He suggested that anhedonia was a central, genetically transmitted defect both in overt schizophrenia and in compensated schizotypes, who do not actually experience a psychotic breakdown. According to Rado, this defect prevented the development of normal healthy sexual functioning, reduced enthusiasm for life, impaired the ability to relate with other people, and weakened the feelings of joy, affection, love, pride, and self-respect.

Meehl $(1962,1973)$ integrated theories by Rado $(1956,1962)$ into a theory of neurological dysfunction in schizophrenia. He considered that low hedonic capacity, or joylessness, was a heritable trait predisposing to the development of schizophrenia and depression.

For most psychiatrists it was Klein's (1974) concept of endogenomorphic depression which revived interest in the concept and notion of anhedonia. The Diagnostic and Statistical Manual of Mental Disorders recognized anhedonia in its third edition, published in 1980 (American Psychiatric Association, 1980), in which the concept of anhedonia was promoted to the position of one of the two pathognomonic features of major depressive disorder (MDD). Klein's (1974) definition "a sharp, unreactive, pervasive impairment of the capacity to experience pleasure, or to respond affectively, to the anticipation of pleasure" was slightly modified to "a loss of interest or pleasure in all or almost all usual activities and pastimes" (Snaith, 1992). Furthermore, for the melancholic subtype of major depression, the anhedonic experience became essential to the definition. Actually the DSM-IV-TR defines anhedonia as diminished interest or pleasure in response to stimuli that were previously perceived as rewarding during a premorbid state (American Psychiatric Association, 2000).

With recent scientific advances in elucidating the genetic basis of psychopathology by identifying endophenotypes, anhedonia gradually gained renewed research attention. The importance of 
anhedonia in psychopathology is stressed by a recent study by Hasler et al. (2004), who demonstrated that anhedonia, together with increased stress reactivity, is the most important candidate for psychopathological endophenotype of major depression.

\section{PSYCHOBIOLOGICAL BASIS OF ANHEDONIA}

From a psychobiological perspective, as proposed by several researchers, anhedonia has a putative neural substrate, the dopaminergic mesolimbic and mesocortical reward circuit, which involves the ventral tegmental area (VTA), the ventral striatum, and part of the prefrontal cortex (Markou and Koob, 1991; Heinz et al., 1994; Isella et al., 2003; Willner et al., 2005).

The reward system is a collection of brain structures which attempts to regulate and control behavior by inducing pleasurable effects. The reward is an operational concept for describing the positive value that an individual ascribes to an object, behavioral act, or internal physical state, and its functions are based directly on behavior modification and indirectly on the sensory properties of rewards.

The major neurochemical pathway of the reward system in the brain involves the dopaminergic mesolimbic and mesocortical pathway. Of these pathways, the mesolimbic pathway plays the major role, and goes from the VTA, via the medial forebrain bundle, to the ventral striatum, including the nucleus accumbens (NAcc), to the amygdala and to the hippocampus; the mesolimbic pathway is most closely associated with associative learning, reward motivation and reinforcement. Indeed, the mesocortical pathway projects to cortical regions, including the anterior cingulate cortex (ACC), the orbital frontal cortex (OFC), the medial prefrontal cortex ( $\mathrm{mPFC}$ ), and the insula; this pathway is strongly associated with working memory, attention, and inhibitory control (Treadway and Zald, 2010).

Dopamine primarily acts on one of five post-synaptic G-protein coupled receptors, called $D_{1}-D_{5}$ (Cooper et al., 2003). These receptors are grouped into two families, defined $\mathrm{D}_{1}$-like (including $\mathrm{D}_{1}$ and $\mathrm{D}_{5}$ receptors) and $\mathrm{D}_{2}$-like $\left(\mathrm{D}_{2}, \mathrm{D}_{3}\right.$, and $\mathrm{D}_{4}$ receptors $)$. Upon receptor stimulation, $\mathrm{D}_{1}$-like receptor stimulation increases adenylate cyclase (AC) activity, though activating protein kinase A (PKA) and subsequently the phosphorylation of various intracellular targets, that way generating "up-states" (Surmeier et al., 2007). In contrast, $\mathrm{D}_{2}$-like receptor stimulation results in decreased AC activity, generating “downstates” (Hernandez-Lopez et al., 2000).

A central dopaminergic dysfunction has been widely proposed as a common neurobiological correlate of the psychopathological expression of anhedonia. Some studies on depressive disorders as a group have supported the hypothesis of a dysfunction of dopamine turnover as reflected by levels of homovanillic acid in cerebrospinal fluid and by assessment of dopamine receptors and neuroendocrine function through postmortem, genetic, or neuroimaging techniques. Strong evidence has come from several studies on the effectiveness of dopamine agonists and antagonists in depressive illness, specifically from the recognition that pharmaceutical agents that enhance dopamine transmission present antidepressant activity (Boyer et al., 1995; Willner, 1995; Smeraldi, 1998; Brunello et al., 1999). The hypothesis by which rewarding events, irrespective of their modality, share the common property of activating the mesolimbic and the mesocortical dopamine system has been widely supported. Conversely, as highlighted by Wise (1982), the inactivation of dopamine function leads to anhedonia; this was suggested by cumulative evidence deriving at first from intracranial stimulation, then from dopaminergic antagonism of neuroleptic drugs, and mostly from studies on the mechanism of action of substances of abuse and psychostimulants (Salamone et al., 1997).

Interesting findings about altered dopamine function in anhedonia come from positron emission tomography (PET) and single photon emission computed tomography (SPECT) imaging of the dopamine transporter (DAT), by using the high-affinity radiotracer $\left[{ }^{123} \mathrm{I}\right] \mathrm{N}$-fluoropropyl-carbomethoxy-3 $\beta$-(4-iodophenyl)tropane (DATSCAN).

While many studies have been conducted about dopamine dysfunction in MDD (Laasonen-Balk et al., 1999; Meyer et al., 2001; Amsterdam and Newberg, 2007; Yang et al., 2008), so far just a single study, conducted by Sarchiapone et al. (2006), focused its attention on individuals affected by MDD with anhedonic symptoms. This study was conducted on a total of 11 depressed outpatients with anhedonia [with a Snaith-Hamilton Pleasure Scale (SHAPS; Snaith et al., 1995) total score $>7$ and an Hamilton Depression Rating Scale (HAM-D; Hamilton, 1960) score > 18] and 9 healthy comparison subjects, by using SPECT with the radiotracer DATSCAN to evaluate DAT binding. Significantly lower specific/non-specific DAT binding ratios were found in the putamen and caudate individually and in the whole striatum bilaterally of depressed patients with anhedonia compared with control subjects.

In addition to dopamine, primarily involved in hedonic experience are endogenous opioids, like endorphins, enkephalins, dynorphins, and orphanin FG as well as their various receptor subtypes $(\mu$, $\delta$, $\kappa$, and ORL1; Cooper et al., 2003), which are widely expressed in the ventral striatum (particularly the shell of the NAcc). Stimulation of these receptors is believed to underlie hedonic responses to food, and other natural rewards (Pecina et al., 2006).

In a recent review, Treadway and Zald (2010), according to the theoretical models of anticipatory and consummatory pleasure (Klein, 1987; Berridge and Robinson, 1998; Depue and Collins, 1999), proposed a distinction between deficits in the hedonic response to rewards (reward "liking"), which leads to consummatory anhedonia, and deficits in the motivation to pursue them (reward "wanting"), which leads to motivational anhedonia. Reward "liking" and, consequently, consummatory anhedonia would be linked to opioids, ventromedial prefrontal cortex, and amygdala, whereas reward "wanting" and motivational anhedonia would be linked to dopamine and basal ganglia. Furthermore, they suppose that it would be necessary to overcome the conceptualization of anhedonia as a steady-state, mood-like phenomenon; consequently, they proposed to introduce the term "decisional anhedonia" to address the influence of anhedonia on reward decision-making.

\section{DIAGNOSING ANHEDONIA}

Although anhedonia is regarded as an important symptom in psychopathology (Snaith, 1993; Berenbaum et al., 2003), so far it has received relatively little attention. This limited attention could be the result of the low availability of short, well-validated, and easy to use instruments (Franken et al., 2007).

In general, two main approaches have been utilized to investigate and assess anhedonia (or hedonic capacity): laboratory-based measures and questionnaires. 
The first approach utilizes laboratory-based measures of anhedonia, involving signal-detection methodology, physiologic measures, and subjective hedonic response to pleasant stimuli (Berenbaum et al., 1987; Fiorito and Simons, 1994; Ferguson and Katkin, 1996; Berlin et al., 1998; Pizzagalli et al., 2005). Besides these behavioral measures, anhedonia can also be evaluated using hemodynamic (Crespo-Facorro et al., 2001; Mitterschiffthaler et al., 2003; Keedwell et al., 2005) and electrophysiological (Simons et al., 1982; Dubal et al., 2000; Franken et al., 2006a) measures.

The secondary approach to the diagnosis of anhedonia involves the use of questionnaires. Several scales have been developed to assess anhedonia or hedonic capacity. Specific scales for the measurement of anhedonia are the Revised Chapman Physical Anhedonia Scale (CPAS) and Social Anhedonia Scale (SAS; Chapman et al., 1976; Chapman and Chapman, 1982); the Fawcett-Clark Pleasure Scale (FCPS; Fawcett et al., 1983); and the SHAPS (Snaith et al., 1995). The SHAPS was built and validated on the responses of a large non-clinical sample from the general population, requested to agree or disagree with 14 different statements of hedonic response in pleasurable situations, which are likely to be encountered by most people; a cut-off value of $\geq 3$ has been obtained to define the presence of anhedonia, and a rough prevalence of anhedonia in the general population less than 5\%; the SHAPS was employed to assess anhedonia in different psychiatric conditions (Lampe et al., 2001; Silver and Shlomo, 2002; Stevens et al., 2002).

Other rating instruments can be employed to evaluate anhedonia within broader psychopathological dimensions, such as those of depression and negative symptoms of schizophrenia. The Scale for the Assessment of Negative Symptoms (SANS; Andreasen, 1989) and particularly the Subscale for Anhedonia (SANSanh) by Andreasen (1989) was used in patients with schizophrenia and with (Bersani et al., 2002) or without (Dollfus and Petit, 1995; Tollefson and Sanger, 1997) abuse of cannabis. The Bech-Rafaelsen Melancholia Scale (BRMS; Bech and Rafaelsen, 1980; Bech, 2002) was administered not only to melancholic patients, but also to acute schizophrenic subjects, in order to rate the latent dimension of depressive and negative symptomatology and it shows a positive correlation with SANS (Muller et al., 2002). Furthermore it is worth mentioning the 10-cm Visual Analogue Scale (VAS; Aitken, 1969; Mottola, 1993) for pleasure and the Temporal Experience of Pleasure Scale (TEPS; Gard et al., 2006), which was developed to assess anticipatory and consummatory pleasure.

\section{ANHEDONIA IN AXIS I DISORDERS}

Anhedonia has been considered crucial for the diagnosis of depression (Klein, 1974, 1987; Loas et al., 1994; Schrader, 1997), and schizophrenia (Andreasen, 1982; Blanchard et al., 2001; Mason et al., 2004; Gooding et al., 2005). It is, besides depressed mood, one of the two core symptoms of depression (American Psychiatric Association, 2000), moreover lack of reactivity and anhedonia are key diagnostic criteria for the DSM-IV-TR melancholic subtype of major depression (American Psychiatric Association, 2000). Anhedonia is also one of the most important negative symptoms frequently observed in schizophrenia (Andreasen and Olsen, 1982; Blanchard, 1998). For example, Blanchard and Cohen (2006) found evidence to suggest that anhedonia is, together with diminished expression, one of the two key features involved in the negative symptom complex of schizophrenia; nevertheless, other studies, like one conducted by Myin-Germeys et al. (2001), indicate that schizophrenics maintain dynamics in their affect.

Although anhedonia plays a very important role in depression and schizophrenia, it is not just limited to them. In fact, anhedonia was linked to anxiety and adjustment disorders (Silverstone, 1991), suicidal ideation (Oei et al., 1990), and successful suicide (Fawcett, 1993). On the other hand, in the model proposed by Loas (1996), a genetically determined low hedonic capacity was regarded as a specific character trait, which, together with aspects like introversion, obsessive-compulsivity, pessimism, and passivity, could represent a risk factor, which could lead, under stress conditions, to unipolar endogenomorphic depression.

Anhedonia is also present in other disorders and dysfunctional behaviors such as Parkinson's disease (Isella et al., 2003), overeating (Davis and Woodside, 2002), and risky behaviors in general (Franken et al., 2006b).

\section{ANHEDONIA IN SUBSTANCE DEPENDENCE DISORDERS}

In addition to mood disorders and schizophrenia, anhedonia is also present in individuals with a substance use disorder.

Several authors suggested that anhedonia is part of the abstinence symptomatology (Gawin and Kleber, 1986) and it is an important factor involved in relapse (Koob and Le Moal, 2001; Volkow et al., 2002). Particularly interesting and worth noting is a study conducted by Ahmed and Koob (1998), in which it was found that, in an animal model, escalated cocaine use could result from a change in the hedonic set point for cocaine rather than from a simple change in sensitivity to the drug. This change, induced by increasing drug availability, suggests that an even longer access to the drug could lead to further increase in the hedonic set point. Therefore this work suggests that anhedonia is an important factor involved in the transition from recreational use to excessive drug intake.

Among substance dependences, anhedonia was found to be a frequent feature in alcoholics and addicted patients during acute and chronic withdrawal (Heinz et al., 1994), as well as in cocaine, stimulant, and cannabis abusers (Gawin et al., 1988; Miller et al., 1993; Bovasso, 2001). In a study performed by Heinz et al. (1994), it was found that anhedonia, dysphoria, and avolition are common symptoms of schizophrenic, depressive, and alcohol-dependent patients during withdrawal. According to the authors these symptoms may be caused by a functional deficit of the dopaminergic transmission in the dopaminergic reward system. This hypothesis was supported by PET and SPECT findings, which showed that a reduced striatal density of unoccupied dopamine $\mathrm{D}_{2}$-receptors is correlated with extrapyramidal side-effects in neuroleptic-treated individuals with schizophrenia and with craving and dysphoria in drug-dependent patients. Similar results were found in a PET study conducted by Volkow et al. (1996), from which emerged that alcoholics show significant reductions in $\mathrm{D}_{2}$-receptors but not in DAT availability when compared with non-alcoholics.

As previously mentioned, anhedonia has been found to be a common feature in withdrawal syndrome and it is due to a central dopaminergic dysfunction. Likewise, a hypodopaminergic state is also related to many substance use disorders (Melis et al., 2005). As emerged in many studies, ethanol withdrawal decreases 
the spontaneous activity of rat VTA dopamine neurons in vivo (Diana et al., 1992, 1993) and mice in vitro (Bailey et al., 1998). The hypoactivity of dopamine neurons correlates with a reduction of extracellular dopamine levels in the NAcc (Rossetti et al., 1992; Diana et al., 1993; Fadda and Rossetti, 1998) and might represent the neural basis of the dysphoric state observed after the abrupt interruption of chronic ethanol intake. Interestingly, this hypodopaminergic state outlasts the physical signs of withdrawal (Diana et al., 1996; Bailey et al., 2001) and can be terminated by administration of ethanol itself (Diana et al., 1993, 1996). Particularly, a study by Diana et al. (1993), conducted in rats withdrawn from chronic ethanol administration, showed that spontaneous firing rates, spikes per burst, and absolute burst firing, but not the number of spontaneously active VTA dopaminergic neurons, were found drastically reduced. Furthermore, dopamine outflow in the NAcc was reduced after abruptly stopping chronic ethanol administration. All these changes, as well as ethanol withdrawal behavioral signs, were reversed by ethanol administration. This reversal suggested that the abrupt cessation of chronic ethanol administration plays a causal role in the reduction of mesolimbic dopaminergic activity seen in the ethanol withdrawal syndrome. Thus these results indicate that during the ethanol withdrawal syndrome the mesolimbic dopaminergic system activity is tonically reduced. Considering the role of the mesolimbic dopaminergic system in the reinforcing properties of ethanol, the depressed activity of this system during the ethanol withdrawal syndrome may be relevant to the dysphoric state associated with ethanol withdrawal in humans.

Along with typical withdrawal symptoms, anhedonia and craving may arise independently during the phase of abstinence from rewarding psychoactive substances, but their intensity, temporal pattern, and responsivity to treatment do not appear to overlap. In the so-called protracted withdrawal, the syndrome that is usually described as depression could be better interpreted as anhedonia, and it cannot be merely attributed to the psychological effects of abstinence (Jaffe et al., 1997). Diana et al. (1996) took into evidence that anhedonia is associated with craving and dysphoric mood in an animal model of alcohol dependence with abrupt ethanol discontinuation. This study indicates that physiological symptoms of ethanol withdrawal syndrome (i.e., tremors, motor impairment, and reduced seizure threshold) and the decline in dopaminergic neuronal activity responsible for anhedonia, show a different time course, with the hypoactivity of the dopaminergic system emerging later and lasting longer.

Similar results were found for morphine (Diana et al., 1995a, 1999; Bonci and Williams, 1997), cannabinoids (Diana et al., 1998a,b; Spiga et al., 2010), and nicotine (Rasmussen and Czachura, 1995; Epping-Jordan et al., 1998; Harrison et al., 2001). Particularly, morphine withdrawal causes a deep decline of firing rate and bursting activity of VTA dopamine neurons (Diana et al., 1995a,b), which persists long after the behavioral signs of withdrawal have ceased (Diana et al., 1999). During acute withdrawal from chronic morphine administration, an upregulation of the cAMP-dependent cascade produces a long-lasting increased probability of GABA release in the VTA (Bonci and Williams, 1996, 1997). Moreover, an increased sensitivity to presynaptic inhibition by both group II metabotropic glutamate receptors (mGluRs) and $\mathrm{GABA}_{\mathrm{B}}$ receptors results in a reduced release of glutamate (Manzoni and Williams, 1999). Therefore, withdrawal from chronic morphine modifies both inhibitory and excitatory inputs to VTA dopamine cells. Interestingly, while VTA dopamine neurons appear to normalize within 2 weeks after acute withdrawal, acute morphine administration produced greater responses in rats with a history of morphine dependence than in controls (Diana et al., 1999). This finding suggests an increased sensitivity of VTA dopamine neurons to morphine itself, which may be relevant to the phenomenon of drug craving and relapse (Diana et al., 1999; Pulvirenti and Diana, 2001). These studies strengthen the notion that VTA dopamine neurons are involved in the subjective adverse components of withdrawal, like dysphoria, rather than in the somatic facets of it.

Cannabinoid withdrawal effects on VTA dopamine neuronal activity (Diana et al., 1998b) are reminiscent of those reported for ethanol and morphine. More interestingly, a reduction in VTA dopamine neuronal function is also observed when somatic signs of withdrawal are not detectable (Diana et al., 1998b). Furthermore, when a withdrawal is pharmacologically induced with the specific cannabinoid antagonist SR 141716A, the somatic signs of withdrawal accompany the dampened VTA dopamine neuronal activity (Diana et al., 1998b). Similar evidence comes from a recent study by Spiga et al. (2010), conducted on rats withdrawn from cannabinoid, which demonstrates that withdrawal from addictive compounds alters functioning of the mesolimbic system and provides direct morphological evidence for functional abnormalities associated with cannabinoid dependence in dopaminergic neurons and their post-synaptic counterpart.

Similarly, nicotine withdrawal produced a decline of firing rate of VTA dopamine neurons that rapidly returned to control levels (Rasmussen and Czachura, 1995; Liu and Jin, 2004). As it was found in the withdrawal from other substances of abuse (Diana et al., 1993, 1995a, 1998b), the number of spontaneously active dopamine neurons was not altered at any time after nicotine withdrawal. Therefore, this evidence, together with other investigations (Diana et al., 1992, 1993, 1995b, 1998b; Bailey et al., 1998, 2001), suggests that the hypodopaminergic state, which accompany the acute phase of withdrawal, is not mediated by depolarization inactivation of dopamine neurons but it reflects most likely alterations of intrinsic properties and extrinsic afferent regulatory mechanisms (Bonci and Williams, 1996, 1997; Manzoni and Williams, 1999; Pulvirenti and Diana, 2001; Diana and Tepper, 2002) modified by a chronic drug regimen and disclosed by withdrawal.

Cocaine withdrawal effects on VTA dopamine neuronal activity seem to affect the burst firing pattern (Gao et al., 1998). In fact, during the early withdrawal phases, it was observed a reduced bursting activity of VTA dopamine cells, which returned to normal within 7 days. In addition, alteration in the sensitivity of $\mathrm{D}_{2}$ receptors seems to play an important role in cocaine-induced modifications of spontaneous activity of VTA dopamine neurons during the first week of withdrawal (Robertson et al., 1991; Ackerman and White, 1992; Gao et al., 1998; Lee et al., 1999; Marinelli et al., 2003). Consequently, short-term treatment with $\mathrm{D}_{2}$ receptor agonists restores the hypodopaminergic neuronal function (Lee et al., 1999; Marinelli et al., 2003), thus representing a potential treatment for intermediate withdrawal phases. 
During amphetamine withdrawal the spontaneous activity of VTA dopamine neurons does not seem to be altered (Lee et al., 1989); however repeated exposure to amphetamine produces long-lasting changes in the modulation of glutamatergic synaptic transmission by amphetamine in the NAcc (Li and Kauer, 2004).

Further evidence of this hypodopaminergic state, which underlies both withdrawal syndrome and anhedonia, comes from more recent imaging studies, as those by Martinez et al. $(2005,2009)$ and Volkow et al. (1996, 1997, 2002), that were previously discussed. Martinez et al. (2005) found that a decrease in $\mathrm{D}_{2}$ receptors and mesolimbic dopamine transmission predisposes animals to consume alcohol. This study measured $\mathrm{D}_{2}$ receptors and dopamine transmission in human alcohol-dependent subjects using PET and [11C]raclopride; subjects were scanned before and after a psychostimulant challenge (amphetamine $0.3 \mathrm{mg} / \mathrm{kg}$ intravenous). In particular, [11C] raclopride binding potential was significantly reduced by $16.6 \%$ in the limbic striatum, $19.2 \%$ in the associative striatum, and $21.3 \%$ in the sensorimotor striatum in alcohol-dependent subjects compared with healthy control. What emerged from this study is that alcohol dependence was associated with a decrease in $\mathrm{D}_{2}$ receptors in each striatal subdivision, whereas amphetamineinduced dopamine release was reduced in the limbic striatum only. Similar results were found by Martinez et al. (2009), in cocainedependent subjects.

Interesting findings about the presence and correlation of anhedonia in substance-related disorders were found by Janiri et al. (2005) about anhedonia and substance-related symptoms in detoxified substance-dependent subjects. In this study 70 patients were enrolled; they came from three different therapeutic settings: a Therapeutic Community, the Day-Hospital of Psychiatry and Drug Dependence of the University General Hospital "A. Gemelli" in Rome, and Self-Help Groups. Furthermore, patients were subdivided into three groups according to the used, or mainly used, drug: dependent on opiates, dependent on alcohol, and dependent on at least two abused substances (multiple substance disorder-MSD). Each patient was abstinent at the time of the study. Anhedonia was investigated through three different measurement scales: the SHAPS (Snaith et al., 1995), the SANS (Andreasen, 1989), and the BRMS (Bech and Rafaelsen, 1980; Bech, 2002). The only cutoff score utilized for a clinical judgment was the SHAPS score $\geq 3$, indicating the presence of anhedonia. Moreover, a $10-\mathrm{cm}$ VAS (Aitken, 1969; Mottola, 1993) for pleasure was also given to directly assess the hedonic capability, while the level of craving for the specific abused substance was evaluated through a $10-\mathrm{cm}$ VAS for craving. According to the substance previously used, no significant interaction effect between the three groups was seen with regard to all the anhedonia scales and VAS for craving, and with regard to anhedonia and craving. However more subtle differences between the groups considered could have been hardly determined because of the paucity of the samples. With regard to the comparison between the groups divided according to the site of recruitment a difference emerged: in the Therapeutic Community group less anhedonic subjects were found than in others, while a significantly lower level of craving was detected in the self-help groups. Since social support and socializing activities are liable to prevent anhedonia and craving (Gilbert et al., 2002), it is conceivable that the supportive and protective setting of the therapeutic community could be effective on anhedonia, while the interactive and substance-oriented approach of the self-help groups could be effective for craving. In conclusion, what emerges from this study is that there are significant interrelations between hedonic capability, craving, and protracted withdrawal, although the strongest association proved to be between hedonic capability and craving; in particular craving is positively associated with anhedonia levels and negatively with hedonic capability. In the data by Janiri et al. (2005) this model appears to properly fit in the opiates-dependent group, probably because in opiate dependence craving is particularly intense due to the concurrence of reward and relief craving.

The data by Janiri et al. (2005) were confirmed and enriched by following studies made by Martinotti et al. (2008a), who found that the positive correlation between the Clinical Institute Withdrawal Assessment for Alcohol (CIWA-Ar; Sullivan et al., 1989) score and anhedonia scales was in line with the hypothesis that the clinical dimension of anhedonia cannot be separated from the other behavioral symptoms of withdrawal and should thus be considered as part of the same process. This study was conducted on 102 detoxified subjects meeting the clinical criteria for Alcohol Dependence in Remission, who were subdivided into four groups according to the length of abstinence. Withdrawal symptomatology was assessed through the CIWA-Ar; whereas the level of craving for alcohol was evaluated through a 10-cm VAS (Aitken, 1969; Mottola, 1993), and anhedonia was investigated through the SHAPS (Snaith et al., 1995) and the Subscale for Anhedonia of the Scale for the Assessment of Negative Symptoms (SANSanh; Andreasen, 1989). Furthermore, a 10-cm VAS for pleasure was given to directly assess the hedonic capability. According to Martinotti et al. (2008a) the strong correlation of some specific withdrawal symptoms like "nausea" and "headache, fullness in head" with anhedonia scales leads to assume that they may represent physical correlates of anhedonia. It is worth noting that the findings describing alcohol addicts as a population in which somatoform disorders are possible (Bott et al., 2005), and the study by Simon et al. (1999), describing gastrointestinal discomfort and headache as two of the most common pain complaints in depressive disorders, are in line with this hypothesis. Moreover, the correlation between anhedonia scales and "orientation and clouding of sensorium" in the groups of subjects abstinent for a period between 90 to 180 and 180 to 365 days, and the increase of this parameter between the four considered groups, lead to consider this symptom as a possible derivate of both protracted withdrawal and the subclinical neuropsychological deterioration, which outlast the detoxification up to 1 year. In fact, patients in this phase of their abstinence may perceive their performances as lower than those expected on the basis of their long-lasting alcohol-free condition; therefore it may represent a component of anhedonia itself, more than a physiologic correlate of protracted withdrawal. On the other hand, craving did not positively correlate with withdrawal symptoms, thus providing evidence that the physical aspects of withdrawal may present a different time course with respect to craving, as previously highlighted by data from Diana et al. (1996) and Heinz et al. (2004). Therefore the results of the study by Martinotti et al. (2008a) suggest that the clinical dimension of anhedonia cannot be separated from the other behavioral symptoms of withdrawal and should thus be 
considered as part of the same process; furthermore it highlights the relevance of protracted withdrawal well beyond the limited period following the abrupt cessation of alcohol intake.

In another study, Martinotti et al. (2008b) investigated the relationships between anhedonia, craving, and temperament and character dimensions in a sample of patients with alcohol and opiate dependence, recruited after a period of detoxification. The authors found that the temperament dimension of novelty seeking (NS; Cloninger et al., 1993) was positively correlated to both craving and anhedonia, with a higher score of NS in the subsample of anhedonic subjects with respect to both non-anhedonic and control subjects. In this study, the possibility that difficulty in experiencing pleasure in psychiatric disorders can lead to the use of psychoactive substances in an attempt to decrease anhedonia, is extended to subjects without psychiatric disorders, who may try substances to counterbalance a tonic state of anhedonia.

The influence of recent clinical and social-environmental factors on hedonic capability and related psychopathology were investigated in a study by Pozzi et al. (2008). This study was conducted on a sample of 70 patients manifesting dependence on alcohol, opiates, or multiple drugs, without severe comorbidity. The measurement scales for anhedonia SHAPS (Snaith et al., 1995), SANS (Andreasen, 1989), and BRMS (Bech and Rafaelsen, 1980; Bech, 2002) were administered together with the European adaptation of the Addiction Severity Index (EuropASI; Blanken et al., 1994; Koeter and Hartgers, 1997). The composite scores from the seven areas of the EuropASI were introduced as independent factors in a stepwise regression analysis having symptom scores of anhedonia as dependent variables. What emerged from this work is that the EuropASI composites do not explain the variability of the scores of anhedonia. Only in few cases the regression models showed a weak predictive capacity for medical status, alcohol use, and drug use composite scores, with $R$-square values ranging from 10 to $22 \%$. In conclusion, this cross-sectional study showed that anhedonia is a psychopathological entity independent from other clinical and psychosocial features of detoxified addicts without severe comorbid psychopathology.

From a psychobiological perspective a relationship has been found between anhedonia, craving, and dysphoric mood with the hypoactivity of the dopaminergic system, particularly in dopamine outflow in the NAcc of rats withdrawn from chronic alcohol administration (Schmidt et al., 2001). Therefore these data confirm the relationship between the hypoactivity of the dopaminergic system and anhedonia in substance use disorders, as supported by previous studies based on animal models (Guyon et al., 1993; Jaffe et al., 1997; Willner, 1997). Nevertheless, in clinical studies a dopamine central receptor dysfunction was shown to occur as a correlate of affective blunting rather than anhedonia (Schmidt et al., 2001).

Imaging studies provided evidence of disrupted sensitivity to natural reinforces in the reward circuits of drug addicted subjects, which could represent a putative mechanism underlying dysphoria and anhedonia experienced during withdrawal (MartinSoelch et al., 2001; Volkow et al., 2002). The same decreased striatal dopaminergic responsiveness was found by Volkow et al. (1997) in detoxified cocaine-dependent subjects with craving and a reduced "high" experienced in specific pleasant situations.

\section{THE TREATMENT OF ANHEDONIA}

What emerged from the previously cited studies is that, in subjects with a substance use disorder, there is a correlation between anhedonia, craving (Janiri et al., 2005), intensity of withdrawal symptoms (Martinotti et al., 2008a), and psychosocial and personality characteristics (Martinotti et al., 2008b; Pozzi et al., 2008). Furthermore, anhedonia and dysphoric mood are associated with the hypoactivity of the dopaminergic system (Guyon et al., 1993; Jaffe et al., 1997; Volkow et al., 1997; Martin-Soelch et al., 2001; Schmidt et al., 2001; Melis et al., 2005).

On this premise many different therapeutic strategies have been developed to treat anhedonia; in general two main approaches have been utilized: psychotherapy and pharmacological treatment.

Among psychotherapeutic techniques, behavioral activation (BA) might be particularly appropriate in cases with motivational anhedonia. BA was initially developed as a component of cognitive behavioral therapy (CBT), from which it differs primarily in its conceptualization of patient cognitions as a ruminative behavior (Dimidjian et al., 2006). The goal of BA is to help patients to identify whether they are engaging in rewarding or non-rewarding behaviors, and to make behavioral choices that are likely to increase exposure to positively reinforcing experiences. As suggested by initial evidence coming from studies by Coffman et al. (2007), BA may surpass CBT by emphasizing an increase in motivated behaviors, particularly with patients diagnosed with comorbid personality disorders. Recent evidence of the efficacy of BA and CBT in anhedonia comes from functional magnetic resonance imaging (fMRI) studies, which have shown that treatment response to CBT results in a progressive decrease in amygdala sensitivity to negative stimuli (Siegle et al., 2006), while successful treatment with BA leads to increased BOLD responses of the striatum during reward anticipation (Dichter et al., 2009).

Among pharmacological treatments the main target is represented by the dopaminergic reward system, which results to be hypoactive in patients experiencing anhedonia. Therefore dopamine-active pharmacotherapies are recommended. These include psychostimulants, dopamine agonists, and the norepinephrine/dopamine reuptake inhibitor bupropion. In particular, bupropion is the most widely used in clinical practice. However, the pharmacological profile of bupropion is complex, and its effects on reward processing in animals and humans may rely on a variety of mechanisms, some of which are still not completely known.

Bupropion has little direct effect on serotonin function (Stahl et al., 2004). Several studies exploring bupropion occupancy of DAT at clinical doses have reported occupancy rates ranging from 14 to $26 \%$ in the striatum (Meyer et al., 2002; Kugaya et al., 2003; Learned-Coughlin et al., 2003); moreover bupropion increases the activity of the intracellular vesicular monoamine transporter 2 (VMAT2) protein, which may enhance extracellular dopamine by increasing available dopamine in presynaptic pools (Rau et al., 2005). Bupropion may also exert specific influence over dopamine function through its action as an inhibitor of the norepinephrine transporter (NET), which is the primary transporter of dopamine in prefrontal regions. More recent work suggested that bupropion decreases the activity of nicotinic acetylcholine receptors (nAChRs; Dwoskin et al., 2006). 
Bupropion may represent a valid treatment for anhedonia, as suggested by animal studies; rats treated with bupropion demonstrated decreased immobility time during the forced swim test (FST) and tail suspension tests (Cryan et al., 2001, 2004), and showed greater willingness to work for food rewards during a progressive ratio task (Bruijnzeel and Markou, 2003). Further evidence over the effectiveness of bupropion in the treatment of symptoms related to anhedonia, comes from studies by Bodkin et al. (1997) and Tomarken et al. (2004).

On the purpose to treat anhedonia, melancholic, and negative symptoms in anhedonic alcoholics, Martinotti et al. (2010) proposed the use of acetyl-L-carnitine (ALC). ALC is an endogenous compound representing a small amount of the physiological pool of carnitines (Juliet et al., 2003). The main physiological role of ALC is to contribute to the homeostasis of coenzyme A, exporting acetyl-CoA groups from the mitochondria (Bremer, 1983). Pharmacologically, it acts as a precursor of acetylcholine (White and Scates, 1990) and stimulates intermediate energy production (Aureli et al., 1990) and cytochrome oxidase activity in mitochondria (Villa and Gorini, 1991). Furthermore ALC modulate, either directly or indirectly through activation of cholinergic receptors, the $N$-methyl-D-aspartate (NMDA) subtype of glutamate receptors (Calvani and Carta, 1992). ALC may facilitate cholinergic neurotransmission either directly or by shuttling acetyl groups that can be used for acetylcholine (Gibson and Shimada, 1980; Janiri and Tempesta, 1983; Burlina et al., 1989; White and Scates, 1990). ALC has an excitatory activity on cortical cholinergic neurons (Nakamura et al., 1998) and moderate synthesis of acetylcholine from ALC has been observed (Falchetto et al., 1971). Janiri et al. (1991) showed that ALC exerted a mild excitatory effect on cortical cholinergic receptors in vivo, providing further evidence of the influence of ALC on the cholinergic system.

With regard to the effect of ALC on dopamine outflow, mostly implicated in alcohol and substance use disorders, carnitine supplementation has been shown to significantly increase the levels of dopamine in the cortex, hippocampus, and striatum of rat brain (Juliet et al., 2003), while animal studies have shown that ALC administration persistently increases dopamine outflow in the NAcc (Scheggi et al., 2004). In addition, the acute administration of ALC increases $\beta$-endorphin and cortisol plasma levels in healthy subjects, and normalizes them in patients with dementia, Alzheimer's disease and depression. The mechanism of action of ALC in depression may involve effects on the cell membrane, GABA neurotransmission, and serotonergic modulation (Tempesta et al., 1985).

A recent study by Martinotti et al. (2011) evaluated the efficacy of ALC, at different dosages, on specific anhedonic symptoms in detoxified alcohol-dependent subjects. Secondary endpoints were the effect of ALC on melancholic and negative symptoms. The study was conducted on 64 alcohol-dependent anhedonic patients, who were subdivided into three groups: 23 received ALC at a dosage of $3 \mathrm{~g} /$ day, 21 received ALC at a dosage of $1 \mathrm{~g} /$ day, and 20 were given placebo. The presence of anhedonic symptoms was determined by the SHAPS (Snaith et al., 1995) and the Visual Analogue Scale for Anhedonia (VASa; Aitken, 1969; Mottola, 1993); negative, and melancholic symptoms were evaluated by the SANS (Andreasen, 1989) and the BRMS (Bech and Rafaelsen, 1980; Bech, 2002). A significant reduction of anhedonia in patients receiving ALC at 1 and $3 \mathrm{~g} /$ day was found. In conclusion, the results of this study indicate the efficacy and safety of ALC in the treatment of anhedonia, melancholia, and negative symptoms in anhedonic alcoholics after 10 days of intravenous therapy. Accordingly, ALC may be considered as a new potentially useful drug for the treatment of anhedonia.

Recent evidences suggest the efficacy of some second-generation antipsychotics on the treatment of anhedonia in a population of alcohol-dependent subject; in particular, recent works highlight the role of aripiprazole (Kenna et al., 2004a,b; Janiri et al., 2007; Martinotti et al., 2007, 2009) and quetiapine (Orsetti et al., 2007, 2009; Martinotti et al., 2008c).

Aripiprazole, rather than antagonizing the $\mathrm{D}_{2}$ receptor, acts as a $\mathrm{D}_{2}$ partial agonist (Lawler et al., 1999; Burstein et al., 2005), as a partial agonist at the 5- $\mathrm{HT}_{1 \mathrm{~A}}$ receptor, and like the other atypical antipsychotics displays an antagonist profile at the $5-\mathrm{HT}_{2 \mathrm{~A}}$ receptor (Jordan et al., 2002; Shapiro et al., 2003). It also antagonizes the $5-\mathrm{HT}_{7}$ receptor and acts as a partial agonist at the $5-\mathrm{HT}_{2 \mathrm{C}}$ receptor, both with high affinity. Aripiprazole has moderate affinity for histamine, $\alpha$-adrenergic, and $\mathrm{D}_{4}$ receptors as well as the serotonin transporter, while it has no appreciable affinity for cholinergic muscarinic acetylcholine receptors (mAChRs; Shapiro et al., 2003). Recently, it has been demonstrated that in $5-\mathrm{HT}_{7}$ receptor knockout mice, aripiprazole does not reduce immobility time in the FST, and actually increases it (Hedlund, 2009; Sarkisyan et al., 2010). This implicates $5-\mathrm{HT}_{7}$ antagonism as playing a major role in the antidepressant effects of aripiprazole, similarly to amisulpride (Abbas et al., 2009; Hedlund, 2009; Sarkisyan et al., 2010).

Martinotti et al. (2009) performed a randomized, double-blind, confrontation trial with naltrexone, which aim was to investigate the efficacy of aripiprazole on alcohol-drinking indices, craving, and psychiatric symptom, such as anhedonia. This study was conducted on 75 alcohol-dependent subjects and demonstrated that patients treated with aripiprazole remained abstinent from any alcohol amount for a longer time with respect to those treated with naltrexone; furthermore aripiprazole was efficacious in attenuating psychopathological symptom severity, including anhedonia; however, as for craving scores, patients treated with naltrexone showed a better outcome.

Quetiapine is a dibenzothiazepine derivative that has a greater affinity for serotonin $5-\mathrm{HT}_{2}$ receptors than dopamine $\mathrm{D}_{2}$ receptors, together with a considerable activity at histamine $\mathrm{H}_{1}$ receptors, $\alpha_{1}$ - and $\alpha_{2}$-adrenergic receptors. Even though quetiapine itself is not able to activate these receptors, it behaves as a competitive antagonist, and therefore prevents the effects of endogenous neurotransmitters at these sites. In addition, quetiapine has partial agonist activity at serotonin $5-\mathrm{HT}_{1 \mathrm{~A}}$ receptors, while it has clinically negligible anticholinergic properties.

Martinotti et al. (2008c) investigated the safety and efficacy of quetiapine in the treatment of alcohol dependence comorbid with disorders characterized by high levels of mood and behavioral instability. This study was conducted on 28 alcohol-dependent subjects and demonstrated that quetiapine decreased alcohol consumption, craving for alcohol, and psychiatric symptoms intensity, including anhedonia, maintaining a good level of tolerance.

Interesting findings about the effects of quetiapine treatment on anhedonia came also from animal study performed by Orsetti et al. $(2007,2009)$. In a study published in 2007 (Orsetti et al., 2007) they 
found that the administration of quetiapine at a dosage of $2 \mathrm{mg} /$ $\mathrm{kg} /$ day, prevents the onset of anhedonia in rats exposed to a 6-week chronic mild stress (CMS) protocol. The effect of quetiapine has a slow onset, beginning at week 5 , and causes a complete recovery from anhedonia. In this respect, the effect of quetiapine is similar to that obtained after chronic administration of amitriptyline 2 or $5 \mathrm{mg} / \mathrm{kg} /$ day. Findings from Orsetti et al. (2007) also indicate that a 6-week administration of quetiapine, 2 or $10 \mathrm{mg} / \mathrm{kg} / \mathrm{day}$, has protective effects against the onset of anhedonia caused by the exposure to an acute subthreshold stressful event in rats that have previously experienced the CMS procedure. Thus, this results suggest that quetiapine is able to prevent both the transient mood depression caused by acute stress and the long-lasting anhedonic state induced by exposure, over a period of weeks, to a variety of unpredictable mild stressors.

In a more recent study, Orsetti et al. (2009) investigated the molecular mechanisms of quetiapine antidepressant effect by coupling the CMS protocol with Affymetrix microarray technology to screen the entire rat genome for gene changes in the frontal cortex. This work showed that the action of quetiapine prevents the stress induced impairment of some processes either involved in central nervous system development or having a crucial role for viability of neural cells and cell to cell communications, like signal transduction regulation, inorganic cation transport, membrane organization, and neurite morphogenesis. Therefore, Orsetti et al. (2009) showed that chronic quetiapine treatment prevented anhedonia and reversed, at least in part, the changes of gene expression induced by CMS in the rat frontal cortex. They also identified that 11 genes (Ptgs2, Gad1, Plcb1, Camk2a, Homer1, Senp2, Junb, Nfib, Hes5, Capon, and Marcks), representing molecular targets of quetiapine, are presumably the effectors of its clinical efficacy.

\section{CONCLUSION}

As originally formulated by Ribot (1896), anhedonia consists of the inability to experience pleasure, and it refers to both a state symptom in various psychiatric disorders and a personality trait. Anhedonia can be found in many psychiatric disorders, such as major depression and mood disorders in general, schizophrenia, as well as in Parkinson's disease, over-eating, and risky behaviors.

\section{REFERENCES}

Abbas, A. I., Hedlund, P. B., Huang, X. P., Tran, T. B., Meltzer,H.Y., and Roth, B.L. (2009). Amisulpride is a potent 5-HT7 antagonist: relevance for antidepressant actions in vivo. Psychopharmacology (Berl.) 205, 119-128.

Ackerman, J. M., and White, F. J. (1992). Decreased activity of rat Al0 dopamine neurons following withdrawal from repeated cocaine. Eur. J. Pharmacol. 21, 171-173.

Ahmed, S. H., and Koob, G. F. (1998). Transition from moderate to excessive drug intake: change in hedonic set point. Science 282, 298-300.

Aitken, R. C. B. (1969). Measurement of feelings using visual analogue scales. Proc. R. Soc. Med. 62, 989.
American Psychiatric Association. (1980). Diagnostic and Statistical Manual of Mental Disorders, 3rd Edn, Text (DSM-III). Washington: American Psychiatric Press.

American Psychiatric Association. (2000). Diagnostic and Statistical Manual of Mental Disorders, 4th Edn, Text Revision (DSM-IV-TR). Washington: American Psychiatric Press.

Amsterdam, J. D., and Newberg, A. B. (2007). A preliminary study of dopamine transporter binding in bipolar and unipolar depressed patients and healthy controls. Neuropsychobiology 55, 167-170.

Andreasen,N.C.(1982). Negative symptoms in schizophrenia: definition and reliability. Arch. Gen. Psychiatry 39, 784-788.

As highlighted by many studies, anhedonia is also a common feature in substance use disorders; it is part of the abstinence symptomatology (Gawin and Kleber, 1986), and several authors suggested that it is an important factor involved in relapse (Koob and Le Moal, 2001; Volkow et al., 2002), as well as in the transition from recreational use to excessive drug intake (Ahmed and Koob, 1998). In particular, anhedonia has been found to be a frequent feature in alcoholics and addicted patients during acute and chronic withdrawal (Heinz et al., 1994), as well as in cocaine, stimulant, and cannabis abusers (Gawin et al., 1988; Miller et al., 1993; Bovasso, 2001). As previously mentioned, interesting findings about the presence and correlation of anhedonia in substance-related disorders have been found by Janiri et al. (2005), who found interrelations between hedonic capability, craving, and protracted withdrawal, especially in opiate-dependent subjects; furthermore Martinotti et al. (2008a) found that the clinical dimension of anhedonia cannot be separated from other behavioral symptoms of withdrawal and should be considered as part of the same process. In another study, Martinotti et al. (2008b) found that the temperament dimension of NS (Cloninger et al., 1993) was positively correlated to both craving and anhedonia, suggesting that difficulty in experiencing pleasure in psychiatric disorders can lead to the use of psychoactive substances in an attempt to decrease anhedonia.

In conclusion, we believe that the importance of anhedonia as a symptom is fundamental and should be thus properly highlighted. As previously noted, anhedonia has relevant implication in the pathogenesis of several psychiatric disorders, of which it represents one of the major symptoms; moreover, it has revealed to have possible treatment implications. In point of fact treating anhedonia, of which the neuropsychobiology has been deeply investigated, could mean treating the underlying pathology. In particular, within substance-dependent disorder, treating anhedonia in detoxified dependent subjects, could be critical in terms of relapse prevention strategies, given its strong relationship with craving, since the higher the craving scores the higher the level of anhedonia. In the attempt to do that ALC has been proposed as a valid treatment strategy. However further larger-scale, controlled clinical trials are needed to assess the efficacy of ALC and other drugs in substance use disorders and other clinical conditions in which anhedonia is a core symptom, such as schizophrenia and depressive disorders.

Andreasen, N. C. (1989). The Scale for the Assessment of Negative Symptoms (SANS): conceptual and theoretical foundations. Br. J. Psychiatry Suppl. 7, 49-58.

Andreasen, N. C., and Olsen, S. (1982). Negative versus positive schizophrenia: definition and validation. Arch Gen. Psychiatry 39, 789-794.

Aureli, T., Miccheli, A., Ricciolini, R., Di Cocco, M. E., Ramacci, M. T., Angelucci, L., Ghirardi, O., and Conti, F. (1990). Aging brain: effect of acetylL-carnitine treatment on rat brain energy and phospholipid metabolism. A study by 31P and 1HNMR spectroscopy. Brain Res. 526, 108-112.

Bailey, C. P., Manley, S. J., Watson, W. P., Wonnacott, S., Molleman, A., and
Little, H. J. (1998). Chronic ethanol administration alters activity in ventral tegmental area neurons after cessation of withdrawal hyperexcitability. Brain Res. 24, 144-152.

Bailey, C. P., O'Callaghan, M. J., Croft, A. P., Manley, S. J., and Little, H. J. (2001). Alterations in mesolimbic dopamine function during the abstinence period following chronic ethanol consumption. Neuropharmacology41,989-999.

Bech, P. (2002). The Bech-Rafaelsen Melancholia Scale (MES) in clinical trials of therapies in depressive disorders: a 20-year review of its use as outcome measure. Acta Psychiatr. Scand. 106, 252-264.

Bech, P., and Rafaelsen, O. J. (1980). The use of rating scales exemplified by a 
comparison of the Hamilton and the Bech-Rafaelsen Melancholia Scale. Acta Psychiatr. Scand. 62(Suppl. 285), 128-132.

Berenbaum, H., Raghavan, C., Le, H. N., Vernon, L. L., and Gomez, J. J. (2003). A taxonomy of emotional disturbances. Clin. Psychol. Sci. Pract. 10, 206-226.

Berenbaum, H., Snowhite, R., and Oltmanns, T.F. (1987). Anhedonia and emotional responses to affect evoking stimuli. Psychol. Med. 17, 677-684.

Berlin, I., Givry-Steiner, L., Lecrubier, Y., and Puech, A. J. (1998). Measures of anhedonia and hedonic responses to sucrose in depressive and schizophrenic patients in comparison with healthy subjects. Eur. Psychiatry 13, 303-309.

Berridge, K. C., and Robinson, T. E. (1998). What is the role of dopamine in reward: hedonic impact, reward learning, or incentive salience? Brain Res. Rev. 28, 309-369.

Bersani, G., Orlandi, V., Gherardelli, S., and Pancheri, P. (2002). Cannabis and neurological soft signs in schizophrenia: absence of relationship and influence on psychopathology. Psychopathology 35, 289-295.

Bevan, L. W. (1899). A Textbook of Mental Diseases. London: Charles Griffin.

Blanchard, J. J. (1998). "Hedonic capacity:implications for understanding emotional and social functioning in schizophrenia," in Emotions in Psychopathology: Theory and Research, edsW.F.Flack and J.D.Laird (New York: Oxford University Press), 336-352.

Blanchard, J. J., and Cohen, A. S. (2006). The structure of negative symptoms within schizophrenia: implications for assessment. Schizophr. Bull. 32, 238-245.

Blanchard, J. J., Horan, W. P., and Brown, S. A. (2001). Diagnostic differences in social anhedonia: a longitudinal study of schizophrenia and major depressive disorder. J. Abnorm. Psychol. 110, 363-371.

Blanken, P., Hendriks, V., Pozzi, G., Tempesta, E., Hartgers, C., Koeter, M., Fahrner, A., Gsellhofer, B., Kufner, H., Kokkevi, A., and Uchtenhagen, A. (1994). European Addiction Severity Index: A Guide to Training and Administering EuropASI Interviews. Bruxelles: COST Report.

Bleuler, E. (1911). Dementia Praecox oder Gruppe der Schizophrenien/Dementia Praecox or the Group of Schizophrenias. New York: International Universities Press.

Bodkin, J. A., Lasser, R. A., Wines J. D. Jr., Gardner, D. M., and Baldessarini, R. J. (1997). Combining serotonin reuptake inhibitors and bupropion in partial responders to antidepres- sant monotherapy. J. Clin. Psychiatry $58,137-145$.

Bonci, A., and Williams, J. T. (1996). A common mechanism mediates longterm changes in synaptic transmission after chronic cocaine and morphine. Neuron 16, 631-639.

Bonci, A., and Williams, J. T. (1997). Increased probability of GABA release during withdrawal from morphine. $J$. Neurosci. 15, 796-803.

Bott, K., Meyer, C., Rumpf, H. J., Hapke, U., and John, U. (2005). Psychiatric disorders among at-risk consumers of alcohol in the general population. J. Stud. Alcohol 66, 246-253.

Bovasso, G. B. (2001). Cannabis abuse as a risk factor for depressive symptoms. Am. J. Psychiatry 158, 2033-2037.

Boyer, P., Lecrubier, Y., Puech, A. J., Dewailly, J., and Aubin, F. (1995). Treatment of negative symptoms in schizophrenia with amisulpride. $B r$. J. Psychiatry 166, 68-72.

Bremer, J. (1983). Carnitine-metabolism and functions. Physiol. Rev. 63, 1420-1480.

Bruijnzeel, A. W., and Markou, A. (2003). Characterization of the effects of bupropion on the reinforcing properties of nicotine and food in rats. Synapse 50, 20-28.

Brunello, N., Akiskal, H., Boyer, P., Gessa, G. L., Howland, R. H., Langer, S. Z., Mendlewicz, J., Paes de Souza, M., Placidi, G. F., Racagni, G., and Wessely, S. (1999). Dysthymia: clinical picture, extent of overlap with chronic fatigue syndrome, neuropsychopharmacological considerations, and new therapeutic vistas. J. Affect. Disord. 52, 275-290.

Bucknill, J. C., and Tuke, D. H. (1874). A Manual of Psychological Medicine. London: Churchill.

Burlina, A. P., Sershen, H., Debler, E. A., and Lajtha, A. (1989). Uptake of acetyl-L-carnitine in the brain. Neurochem. Res. 14, 489-493.

Burstein, E. S., Ma, J., Wong, S., Gao, Y., Pham, E., Knapp, A. E., Nash, N. R., Olsson, R., Davis, R. E., Hacksell, U., Weiner, D. M., and Brann, M. R. (2005). Intrinsic efficacy of antipsychotics at human D2, D3, and D4 dopamine receptors: identification of the clozapine metabolite $\mathrm{N}$-desmethylclozapine as a D2/D3 partial agonist. J. Pharmacol. Exp. Ther. 315, 1278-1287.

Calvani, M., and Carta, A. (1992). "AcetylL-carnitine: its role in neuronal metabolism," in Alzheimer's DiseaseNew Treatment Strategies, eds Z. S. Khachaturian and J. P. Blass (New York: Marcel Dekker), 223-229.

Chapman, L. J., and Chapman, J. P. (1982). The Revised Physical Anhedonia Scale. Madison: University of Wisconsin.

Chapman, L. J., Chapman, J. P., and Raulin, M. L. (1976). Scales for physi- cal and social anhedonia. J. Abnorm. Psychol. 85, 374-382.

Cloninger, C. R., Svrakic, D. M., and Przybeck, T. R. (1993). A psychobiological model of temperament and character. Arch. Gen. Psychiatry 50, 975-989.

Clouston, T. S. (1896). Clinical Lectures on Mental Diseases. London: Churchill.

Coffman, S. J., Martell, C. R., Dimidjian, S., Gallop, R., and Hollon, S. D. (2007). Extreme nonresponse in cognitive therapy: can behavioral activation succeed where cognitive therapy fails? J. Consult. Clin. Psychol. 75, 531-541.

Cooper, J. C., Bloom, F. E., and Roth, R. H. (2003). The Biochemical Basis of Neuropharmacology, 8th Edn. New York: Oxford University Press.

Crespo-Facorro, B., Paradiso, S. Andreasen, N. C., O'Leary, D. S., Watkins, G. L., Ponto, L. L., and Hichwa, R. D. (2001). Neural mechanism of anhedonia in schizophrenia: a PET study of response to unpleasant and pleasant odors. JAMA 286, 427-435.

Cryan, J. F., Dalvi, A., Jin, S. H., Hirsch, B. R., Lucki, I., and Thomas, S. A. (2001). Use of dopamine-beta-hydroxylasedeficient mice to determine the role of norepinephrine in the mechanism of action of antidepressant drugs. J. Pharmacol. Exp. Ther. 298, 651-657.

Cryan, J. F., O'Leary, O. F., Jin, S. H., Friedland, J.C., Ouyang, M., Hirsch, B. R., Page, M. E., Dalvi, A., Thomas, S.A., and Lucki, I. (2004). Norepinephrinedeficient mice lack responses to antidepressant drugs, including selective serotonin reuptake inhibitors. Proc Natl. Acad. Sci.U.S.A. 101, 8186-8191.

Davis, C., and Woodside, D. B. (2002). Sensitivity to the rewarding effects of food and exercise in the eating disorders. Compr. Psychiatry 43, 189-194.

Depue, R. A., and Collins, P. F. (1999). Neurobiology of the structure of personality: dopamine, facilitation of incentive motivation, and extraversion. Behav. Brain Sci. 22, 491-569.

Diana, M., Melis, M., and Gessa, G. L. (1998a). Increase in meso-prefrontal dopaminergic activity after stimulation of $\mathrm{CB} 1$ receptors by cannabinoids. Eur. J. Neurosci. 10, 2825-2830.

Diana, M., Melis, M., Muntoni, A. L., and Gessa, G. L. (1998b). Mesolimbic dopaminergic decline after cannabinoid withdrawal. Proc. Natl. Acad. Sci. U.S.A. 18, 10269-10273.

Diana, M., Muntoni, A. L., Pistis, M., Melis, M., and Gessa, G. L. (1999). Lasting reduction in mesolimbic dopamine neuronal activity after morphine withdrawal. Eur. J. Neurosci. 11, 1037-1041.

Diana, M., Pistis, M., Carboni, S., Gessa, G. L., and Rossetti,Z.L. (1993). Profound decrement of mesolimbic dopaminergic neuronal activity during ethanol withdrawal syndrome in rats: electrophysiological and biochemical evidence. Proc. Natl. Acad. Sci. U.S.A. 1, 7966-7969.

Diana, M., Pistis, M., Muntoni, A., and Gessa, G. (1996). Mesolimbic dopaminergic reduction outlasts ethanol withdrawal syndrome: evidence of protracted abstinence. Neuroscience 71, 411-415.

Diana, M., Pistis, M., Muntoni, A., and Gessa, G. L. (1995a). Profound decrease of mesolimbic dopaminergic neuronal activity in morphine withdrawn rats. J. Pharmacol. Exp. Ther. 272, 781-785.

Diana, M., Pistis, M., Muntoni, A. L., and Gessa, G. L. (1995b). Ethanol withdrawal does not induce a reduction in the number of spontaneously active dopaminergic neurons in the mesolimbic system. Brain Res. 5, 29-34.

Diana, M., Pistis, M., Muntoni, A., Rossetti, Z. L., and Gessa, G. (1992). Marked decrease of A10 dopamine neuronal firing during ethanol withdrawal syndrome in rats. Eur. J. Pharmacol. 20, 403-404.

Diana, M., and Tepper, J. M. (2002) "Electrophysiological pharmacology of mesencephalic dopaminergic neurons," in Handbook of Experimental Pharmacology, Vol. 154/II, Dopamine in the CNS II, ed. G. Di Chiara (Berlin: Springer-Verlag), 1-62.

Dichter, G. S., Felder, J.N., Petty, C., Bizzell, J., Ernst, M., and Smoski, M. J. (2009). The effects of psychotherapy on neural responses to rewards in major depression. Biol. Psychiatry 66, 886-897.

Dimidjian, S., Hollon, S. D., Dobson, K. S., Schmaling, K. B., Kohlenberg, R. J., Addis, M.E., Gallop, R., McGlinchey, J. B., Markley, D. K., Gollan, J. K., Atkins, D. C., Dunner, D. L., and Jacobson, N. S. (2006). Randomized trial of behavioral activation, cognitive therapy, and antidepressant medication in the acute treatment of adults with major depression. J. Consult. Clin. Psychol. 74, 658-670.

Dollfus, S., and Petit, M. (1995). Negative symptoms in schizophrenia: their evolution during an acute phase. Schizophr. Res. 17, 187-194.

Dubal, S., Pierson, A., and Jouvent, R. (2000). Focussed attention in anhedonia: a P3 study. Psychophysiology 37, 711-714.

Dwoskin, L. P., Rauhut, A. S., KingPospisil, K. A., and Bardo, M. T. (2006). Review of the pharmacology and clinical profile of bupropion, an antidepressant and tobacco use cessation agent. CNS Drug Rev. 12, 178-207.

Epping-Jordan, M. P., Watkins, S. S., Koob, G. F., and Markou, A. (1998). 
Dramatic decreases in brain reward function during nicotine withdrawal. Nature 7, 76-79.

Fadda, F., and Rossetti, Z. L. (1998). Chronic ethanol consumption: from neuroadaptation to neurodegeneration. Prog. Neurobiol. 56, 385-431.

Falchetto, S., Kato, G., and Provini, L. (1971). The action of carnitines on cortical neurons. Can. J. Physiol. Pharmacol. 49, 1-7.

Fawcett, J. (1993). The morbidity and mortality of clinical depression. Special issue: affective disorders: current and future perspectives. Int. Clin. Psychopharmacol. 8, 217-220.

Fawcett, J., Clark, D. C., Scheftner, W. A., and Gibbons, R. D. (1983). Assessing anhedonia in psychiatric patients. Arch. Gen. Psychiatry 40, 79-84.

Ferguson, M. L., and Katkin, E. S. (1996). Visceral perception, anhedonia, and emotion. Biol. Psychol. 42, 131-145.

Fiorito, E. R., and Simons, R. F. (1994). Emotional imagery and physical anhedonia. Psychophysiology 31, 513-521.

Franken, I. H. A., Rassin, E., and Muris, P. (2007). The assessment of anhedonia in clinical and non-clinical populations: further validation of the SnaithHamilton Pleasure Scale (SHAPS). J. Affect. Disord. 99, 83-89.

Franken, I. H. A., Van Strien, J. W., and Nijs, I. (2006a). Effect of hedonic tone on event-related potential measures of cognitive processing. Psychiatry Res. 142, 233-239.

Franken, I. H. A., Zijlstra, C., and Muris, P. (2006b). Are nonpharmacological induced rewards related to anhedonia? A study among skydivers. Prog. Neuropsychopharmacol. Biol. Psychiatry 30, 297-300.

Gao, W. Y., Lee, T. H., King, G. R., and Ellinwood, E. H. (1998). Alterations in baseline activity and quinpirole sensitivity in putative dopamine neurons in the substantia nigra and ventral tegmental area after withdrawal from cocaine pretreatment. Neuropsychopharmacology 18, 222-232.

Gard, D.E., Gard, M. G., Kring, A. M., and John, O. P. (2006). Anticipatory and consummatory components of the experience of pleasure: a scale development study. J. Res. Pers. 40, 1086-1102.

Gawin, F. H., and Ellinwood, E. H. Jr. (1988). Cocaine and other stimulants. Actions, abuse and treatment. N. Engl. J. Med. 318, 1173-1182.

Gawin, F. H., and Kleber, H. D. (1986). Abstinence symptomatology and psychiatric diagnosis in cocaine abusers. Arch. Gen. Psychiatry 43, 107-113.

Gibson, G. E., and Shimada, M. (1980) Studies on the metabolic pathway of the acetyl group for acetylcholine syntesis. Biochem. Pharmacol. 29, 167-174.
Gilbert, P., Allan, S., Brough, S., Melley, S., and Miles, J.N.V.(2002). Relationship of anhedonia and anxiety to social rank, defeat and entrapment. J. Affect. Disord. 71, 141-151.

Gooding, D. C., Tallent, K. A., and Matts, C. W. (2005). Clinical status of atrisk individuals 5 years later: further validation of the psychometric highrisk strategy. J. Abnorm. Psychol. 114, 170-175.

Guyon, A., Assouly-Besse, F., Biala, G., Puech, A. J., and Thiébot, M. H. (1993). Potentiation by low doses of selected neuroleptics of foodinduced conditioned place preference in rats. Psychopharmacology 110, 460-466.

Hamilton, M. (1960). A rating scale for depression. J. Neurol. Neurosurg. Psychiatr. 23, 56-62.

Harrison, A. A., Liem, Y. T., and Markou, A. (2001). Fluoxetine combined with a serotonin-1A receptor antagonist reversed reward deficits observed during nicotine and amphetamine withdrawal in rats. Neuropsychopharmacology 25, 55-71.

Hasler, G., Drevets, W. C., Manji, H. K. and Charney, D.S. (2004). Discovering endophenotypes for major depression. Neuropsychopharmacology 29, 1765-1781.

Hedlund, P.B. (2009). The 5-HT7 receptor and disorders of the nervous system: an overview. Psychopharmacology (Berl.) 206, 345-354.

Heinz, A., Schmidt, L. G., and Reischies, F. M. (1994). Anhedonia in schizophrenic, depressed, or alcohol dependent patients: neurobiological correlates. Pharmacopsychiatry 27, 7-10.

Heinz, A., Siessmeier, T., Wrase, J., Hermann, D., Klein, S., Grüsser, S.M., Flor, H., Braus, D.F., Buchholz, H.G. Gründer, G., Schreckenberger, M., Smolka, M.N., Rösch, F., Mann, K., and Bartenstein, P. (2004). Correlation between dopamine $\mathrm{D}(2)$ receptors in the ventral striatum and central processing of alcohol cues and craving. Am. J. Psychiatry 161, 1741-1742.

Hernandez-Lopez, S., Tkatch, T., PerezGarci, E., Galarraga, E., Bargas, J., Hamm, H., and Surmeier, D. J. (2000). D2 dopamine receptors in striatal medium spiny neurons reduce L-type $\mathrm{Ca} 2+$ currents and excitability via a novel PLC[beta]1-IP3-calcineurinsignaling cascade. J. Neurosci. 20, 8987-8995.

Isella, V., Iurlaro, S., Piolti, R., Ferrarese, C. Frattola,L.,Appollonio, I., Melzi, P., and Grimaldi, M. (2003). Physical anhedonia in Parkinson's disease. J. Neurol. Neurosurg. Psychiatr. 74, 1308-1311.

Jaffe, H., Knappe, C. M., and Ciraulo, D. A. (1997). "Opiates: clinical aspects," in Substance Abuse - A Comprehensive Textbook, 3rdEdn, eds J. H. Lowinson, P. Ruiz, R.B. Millman, and J.G. Langrod (Baltimore, MD: Williams \& Wilkins), 158-166.

Janiri, L., Falcone, M., Persico, A., and Tempesta, E. (1991). Activity of L-carnitine and L-acetylcarnitine on cholinoceptive neocortical neurons of the rat in vivo. J. Neural Transm. Gen. Sect. 86, 135-146.

Janiri, L., Martinotti, G., Dario, T., Reina, D., Paparello, F., Pozzi, G., Addolorato, G., Di Giannantonio, M., and De Risio, S. (2005). Anhedonia and substancerelated symptoms in detoxified substance dependent subjects: a correlation study. Neuropsychobiology 52 , 37-44.

Janiri, L., Martinotti, G., and Di Nicola, M. (2007). Aripiprazole for relapse prevention and craving in alcoholdependent subjects: results from a pilot study. J. Clin. Psychopharmacol. 27, 519-520.

Janiri, L., and Tempesta, E. (1983). A pharmacological profile of the effects of carnitine and acetyl carnitine on the central nervous system. Int. J. Clin. Pharmacol. Res. 3, 295-306.

Jaspers, K. (1913). Allgemeine Psychopathologie. Ein Leitfaden für Studierende, Ärzte und Psychologen. 1. Auflage. Berlin: Springer.

Jordan, S., Koprivica, V., Chen, R., Tottori, K., Kikuchi, T., and Altar, C. A. (2002) The antipsychotic aripiprazole is a potent, partial agonist at the human 5-HT1A receptor. Eur. J. Pharmacol. 441, 137-140.

Juliet, P. A., Balasubramaniam D., Balasubramaniam, N., and Panneerselvam, C. (2003). Carnitine: a neuromodulator in aged rats. $J$. Gerontol. A Biol. Sci. Med. Sci. 58 970-974.

Keedwell, P. A., Andrew, C., Williams, S. C., Brammer, M. J., and Phillips, M. L. (2005). The neural correlates of anhedonia in major depressive disorder Biol. Psychiatry 58, 843-853.

Kenna, G. A., McGeary, J. E., and Swift, R. M. (2004a). Pharmacotherapy, pharmacogenomics, and the future of alcohol dependence treatment, part 1. Am J. Health Syst. Pharm. 61, 2272-2279.

Kenna, G. A., McGeary, J. E., and Swift, R. M. (2004b). Pharmacotherapy, pharmacogenomics, and the future of alcohol dependence treatment, part 2. Am. J. Health Syst. Pharm. 61, 2380-2388.

Klein, D. (1974). Endogenomorphic depression. A conceptual and terminological revision. Arch. Gen. Psychiatry 31, 447-454.

Klein, D. (1987). "Depression and anhedonia," in Anhedonia and Affect Deficit States, eds C. Clark and J. Fawcett (New York: PMA Publishing), 1-14.
Koeter, M. W., and Hartgers, C. (1997) Preliminary Procedure for the Computation of the EuropASI Composite Scores. Amsterdam: The Amsterdam Institute for Addiction Research.

Koob, G. F., and Le Moal, M. (2001). Drug addiction, dysregulation of reward, and allostasis. Neuropsychopharmacology 24, 97-129.

Kraepelin, E. (1919). Dementia Praecox and Paraphrenia. New York: Huntington.

Kugaya, A., Seneca, N. M., Snyder, P. J., Williams, S. A., Malison, R. T. Baldwin, R. M., Seibyl, J. P., and Innis, R. B. (2003). Changes in human in vivo serotonin and dopamine transporter availabilities during chronic antidepressant administration. Neuropsychopharmacology 28, 413-420.

Laasonen-Balk, T., Kuikka, J., Viinamaki, H., Husso-Saastamoinen, M., Lehtonen, J., and Tiihonen, J. (1999). Striatal dopamine transporter density in major depression. Psychopharmacology (Berl.) 144, 282-285.

Lampe, I. K., Kahn, R. S., and Heeren, T. J. (2001). Apathy, anhedonia, and psychomotor retardation in elderly psychiatric patients and healthy elderly individuals. J. Geriatr. Psychiatry Neurol. 14, 11-16.

Lawler, C. P., Prioleau, C., Lewis, M. M., Mak, C., Jiang, D., Schetz, J. A. Gonzalez, A. M., Sibley, D. R., and Mailman, R. B. (1999). Interactions of the novel antipsychotic aripiprazole (OPC-14597) with dopamine and serotonin receptor subtypes. Neuropsychopharmacology 20 , 612-627.

Learned-Coughlin, S. M., Bergstrom, M., Savitcheva, I., Ascher, J., Schmith, V. D., and Langstrom, B. (2003). In vivo activity of bupropion at the human dopamine transporter as measured by positron emission tomography. Biol. Psychiatry 54, 800-805.

Lee, T. H., and Ellinwood, E. H. Jr. (1989). Time-dependent changes in the sensitivity of dopamine neurons to low doses of apomorphine following amphetamine infusion. Brain Res. 27, 17-29.

Lee, T. H., Gao, W. Y., Davidson, C., and Ellinwood, E. H. (1999). Altered activity of midbrain dopamine neurons following 7 -day withdrawal from chronic cocaine abuse is normalized by D2 receptor stimulation during the early withdrawal phase. Neuropsychopharmacology 21 127-136.

Li, Y., and Kauer, J. A. (2004). Repeated exposure to amphetamine disrupts dopaminergic modulation of excitatory synaptic plasticity 
and neurotransmission in nucleus accumbens. Synapse 51, 1-10.

Liu, Z. H., and Jin, W.Q. (2004). Decrease of ventral tegmental area dopamine neuronal activity in nicotine withdrawal rats. Neuroreport 28, 1479-1481.

Loas, G. (1996). Vulnerability to depression: a model centered on anhedonia. J. Affect. Disord. 41, 39-53.

Loas, G., Perot, J. M., Hardy, P., and Jouvent, R. (1994). Physical anhedonia and subtypes of major depressive disorder. Eur. Psychiatry 9, 304-306.

Loas, G., and Pierson, A. (1989). Anhedonia in psychiatry: a review. Ann. Med. Psychol. (Paris) 147, 705-717.

Manzoni, O. J., and Williams, J. T. (1999). Presynaptic regulation of glutamate release in the ventral tegmental area during morphine withdrawal. $J$. Neurosci. 1, 6629-6636.

Marinelli, M., Cooper, D. C., Baker, L. K., and White, F. J. (2003). Impulse activity of midbrain dopamine neurons modulates drug-seeking behavior. Psychopharmacology (Berl.) 168, 84-98.

Markou, A., and Koob, G. F. (1991). Postcocaine anhedonia. An animal model of cocaine withdrawal. Neuropsychopharmacology 4, 17-26.

Martinez, D., Gil, R., Slifstein, M., Hwang, D. R., Huang, Y., Perez, A., Kegeles, L., Talbot, P., Evans, S., Krystal, J., Laruelle, M., and Abi-Dargham, A. (2005). Alcohol dependence is associated with blunted dopamine transmission in the ventral striatum. Biol. Psychiatry $58,779-786$.

Martinez, D., Greene, K., Broft, A., Kumar, D., Liu, F., Narendran, R., Slifstein, M., Van Heertum, R., and Kleber, H. D. (2009). Lower level of endogenous dopamine in patients with cocaine dependence: findings from PET imaging of $\mathrm{D} 2 / \mathrm{D} 3$ receptors following acute dopamine depletion. Am. J. Psychiatry 166, 1170-1177.

Martinotti, G., Andreoli, S., Reina, D., Di Nicola, M., Ortolani, I., Tedeschi, D., Fanella, F., Pozzi, G., Iannoni, E., D'Iddio,S., and Janiri,L. (2011). Acetyl-1Carnitine in the treatment of anhedonia, melancholic and negative symptoms in alcohol dependent subjects. Prog. Neuropsychopharmacol. Biol. Psychiatry. doi: 10.1016/j.pnpbp.2011.01.013 [Epub ahead of print].

Martinotti, G., Di Nicola, M., Di Giannantonio, M., and Janiri, L. (2009). Aripiprazole in the treatment of patients with alcohol dependence: a double-blind, comparison trial vs. naltrexone. J. Psychopharmacol. 23, 123-129.

Martinotti, G., Di Nicola, M., and Janiri, L. (2007). Efficacy and safety of aripiprazole in alcohol dependence. Am. J. Drug Alcohol Abuse 33, 393-401.

Martinotti, G., Di Nicola, M. D., Reina, D., Andreoli, S., Focà, F., Cunniff, A., Tonioni, F., Bria, P., and Janiri, L. (2008a).Alcohol protracted withdrawal syndrome: the role of anhedonia. Subst. Use. Misuse 43, 271-284.

Martinotti, G., Cloninger, C. R., and Janiri, L. (2008b). Temperament and character inventory dimensions and anhedonia in detoxified substance-dependent subjects. Am. J. Drug Alcohol Abuse 34, 177-183.

Martinotti, G., Andreoli, S., Di Nicola, M., Di Giannantonio, M., Sarchiapone, M., and Janiri, L. (2008c). Quetiapine decreases alcohol consumption, craving, and psychiatric symptoms in dually diagnosed alcoholics. Hum. Psychopharmacol. 23, 417-424.

Martinotti, G., Reina, D., Di Nicola, M., Andreoli, S., Tedeschi, D., Ortolani, I., Pozzi, G., Iannoni, E., D’Iddio, S., and Janiri, L. (2010). Acetyl-L-carnitine for alcohol craving and relapse prevention in anhedonic alcoholics: a randomized, double-blind, placebo-controlled pilot trial. Alcohol Alcohol. 45, 449-455.

Martin-Soelch, C., Chevalley, A. F., Kunig, G., Missimer, J., Magyar, S., and Mino, A. (2001). Changes in reward-induced brain activation in opiate addicts. Eur. J. Neurosci. 14, 1360-1368.

Mason, O., Startup, M., Halpin, S., Schall, U., Conrad, A., and Carr, V. (2004). Risk factors for transition to first episode psychosis among individuals with 'at-risk mental states'. Schizophr. Res. 71, 227-237.

Meehl, P. E. (1962). Schizotaxia, schizotypy, schizophrenia. Am. Psychol. 17, 827-838.

Meehl, P. E. (1973). Psychodiagnosis. Selected Papers. Minneapolis: University of Minnesota Press.

Melis, M., Spiga, S., and Diana, M. (2005). The dopamine hypothesis of drug addiction: hypodopaminergic state. Int. Rev. Neurobiol. 63, 101-154.

Meyer, J. H., Goulding, V. S., Wilson, A. A., Hussey, D., Christensen, B. K., and Houle, S. (2002). Bupropion occupancy of the dopamine transporter is low during clinical treatment. Psychopharmacology (Berl.) 163, 102-105.

Meyer, J. H., Kruger, S., Wilson, A. A., Christensen, B. K., Goulding, V. S., Schaffer, A., Minifie, C., Houle, S., Hussey, D., and Kennedy, S. H. (2001). Lower dopamine transporter binding potential in striatum during depression. Neuroreport 12, 4121-4125.

Miller, N.S., Summers, G. L., and Gold, M. S. (1993). Cocaine dependence: alcohol and other drug dependence and withdrawal characteristics. J. Addict. Dis. 12, 25-35.
Mitterschiffthaler,M. T., Kumari,V., Malhi, G. S., Brown, R. G., Giampietro, V. P., Brammer, M. J., Suckling, J., Poon, L. Simmons, A., Andrew, C., and Sharma T. (2003). Neural response to pleasant stimuli in anhedonia: an fMRI study. Neuroreport 14, 177-182.

Mottola, C. A. (1993). Measurement strategies: the visual analogue scale. Decubitus 6, 56-58.

Muller, M. J., Wetzel, H., and Benkert, O. (2002). Differential effects of highdose amisulpride versus flupentixol on latent dimensions of depressive and negative symptomatology in acute schizophrenia: an evaluation using confirmatory factor analysis. Int. Clin. Psychopharmacol. 17, 249-261.

Myerson, A. (1923). Anhedonia. Am. J. Psychiatry 2, 87-103.

Myin-Germeys, I., van Os, J., Schwartz, J. E., Stone, A. A., and Delespaul, P. A. (2001). Emotional reactivity to daily life stress in psychosis. Arch. Gen Psychiatry 58, 1137-1144.

Nakamura, J., Koh, N., Sakakibara, F. Hamada,Y., Hara, T., Sasaki, H., Chaya, S., Komori, T., Nakashima, E., Naruse, K., Kato, K., Takeuchi, N., Kasuya, Y., and Hotta, N. (1998). Polyol pathway hyperactivity is closely related to carnitine deficiency in the pathogenesis of diabetic neuropathy of streptozocindiabetic rats. J. Pharmacol. Exp. Ther 287, 897-902.

Oei, T. I., Verhoeven, W. M., Westenberg, H. G., Zwart, F. M., and van Ree, J. M. (1990). Anhedonia, suicide ideation and dexamethasone nonsuppression in depressed patients. J. Psychiatr. Res. 24, 25-35.

Orsetti, M., Canonico, P. L., Dellarole, A., Colella, L., Di Brisco, F., and Ghi, P. (2007). Quetiapine prevents anhedonia induced by acute or chronic stress. Neuropsychopharmacology 32, 1783-1790.

Orsetti, M., Di Brisco, F., Rinaldi, M., Dallorto, D., and Ghi, P. (2009). Some molecular effectors of antidepressant action of quetiapine revealed by DNA microarray in the frontal cortex of anhedonic rats. Pharmacogenet. Genomics 19, 600-612.

Pecina, S., Smith, K. S., and Berridge, K.C. (2006). Hedonic hot spots in the brain. Neuroscientist 12, 500-511.

Pizzagalli, D. A., Jahn, A. L., and O'Shea, J. P. (2005). Toward an objective characterization of an anhedonic phenotype: a signal-detection approach. Biol Psychiatry 57, 319-327.

Pozzi, G., Martinotti, G., Reina, D., Dario, T., Frustaci, A., Janiri, L., and Bria, P. (2008). The assessment of post-detoxification anhedonia: influence of clinical and psychosocial variables. Subst. Use Misuse 43, 722-732.
Pulvirenti, L., and Diana, M. (2001). Drug dependence as a disorder of neural plasticity: focus on dopamine and glutamate. Rev. Neurosci. 12, 141-158.

Rado, S. (1956). Psychoonalysis of Behavior: Collected Papers. New York: Grune \& Stratton.

Rado, S. (1962). Psychoanalysis of Behavior: Collected Papers, Vol. 2. New York: Grune \& Stratton.

Rasmussen, K., and Czachura, J. F. (1995). Nicotine withdrawal leads to increased firing rates of midbrain dopamine neurons. Neuroreport 29, 329-332.

Rau, K. S., Birdsall, E., Hanson, J. E., Johnson-Davis, K. L., Carroll, F. I., Wilkins, D. G., Gibb, J. W., Hanson, G. R., and Fleckenstein, A. E. (2005). Bupropion increases striatal vesicular monoamine transport. Neuropharmacology 49, 820-830.

Ribot, T. (1896). La Psychologie Des Sentiments. Paris: Felix Alcan.

Robertson, M. W., Leslie, C. A., and Bennet, J. P. Jr. (1991). Apparent synaptic dopamine deficiency induced by withdrawal from chronic cocaine treatment. Brain Res. 538, 337-339.

Rossetti,Z.L., Melis, F., Carboni, S., Diana, M., and Gessa, G. L. (1992). Alcohol withdrawal in rats is associated with a marked fall in extraneuronal dopamine. Alcohol. Clin. Exp. Res. 16, 529-532.

Salamone, J.D., Cousins, M. S., and Snyder, B. J. (1997). Behavioral functions of nucleus accumbens dopamine: empirical and conceptual problems with the anhedonia hypothesis. Neurosit. Biobehav. Rev. 21, 341-359.

Sarchiapone, M., Carli, V., Camardese, G., Cuomo, C., Di Giuda, D., Calcagni, M. L., Focacci, C., and De Risio, S. (2006). Dopamine transporter binding in depressed patients with anhedonia. Psychiatry Res. 147, 243-248.

Sarkisyan, G., Roberts, A. J., and Hedlund, P. B. (2010). The 5-HT7 receptor as a mediator and modulator of antidepressant-like behavior. Behav. Brain Res. 209, 99-108.

Scheggi, S., Rauggi, R., Nanni, G., Tagliamonte, A., and Gambarana, C. (2004). Repeated acetyl-L-carnitine administration increases phosphoThr34 DARPP-32 levels and antagonizes cocaine-induced increase in Cdk5 and phospho-Thr75 DARPP-32 levels in rat striatum. Eur. J. Neurosci. 19, 1609-1620.

Schmidt, K., Nolte-Zenker, B., Patzer, J., Bauer, M., Schmidt, L. G., and Heinz, A. (2001). Psychopathological correlates of reduced dopamine receptor sensitivity in depression, schizophrenia, and opiate and alcohol dependence. Pharmacopsychiatry 34, 66-72.

Schrader, G. D. (1997). Does anhedonia correlate with depression severity in 
chronic depression? Compr. Psychiatry 38, 260-263.

Shapiro, D. A., Renock, S., Arrington, E., Chiodo, L. A., Liu, L. X., Sibley, D. R., Roth, B. L., and Mailman, R. (2003). Aripiprazole, a novel atypical antipsychotic drug with a unique and robust pharmacology. Neuropsychopharmacology 28, 1400-1411.

Siegle, G. J., Carter, C. S., and Thase, M. E. (2006). Use of FMRI to predict recovery from unipolar depression with cognitive behavior therapy. Am. J. Psychiatry 163, 735-738.

Silver, H., and Shlomo, N. (2002). Anhedonia and schizophrenia: how much is in the eye of the beholder? Compr. Psychiatry 43, 65-68.

Silverstone, P. H. (1991). Is anhedonia a good measure of depression? Acta Psychiatr. Scand. 83, 249-250.

Simon, G. E., Von Korff, M., Piccinelli, M., Fullerton, C., and Ormel, J. (1999). An international study of the relation between somatic symptoms and depression. N. Engl. J. Med. 341, 1329-1335.

Simons, R. F., MacMillan, F. W. III, and Ireland, F. B. (1982). Anticipatory pleasure deficit in subjects reporting physical anhedonia: slow cortical evidence. Biol. Psychol. 14, 297-310.

Smeraldi, E. (1998). Amisulpride versus fluoxetine in patients with dysthymia or major depression in partial remission: a double-blind, comparative study. J. Affect. Disord. 48, 47-56.

Snaith, P. (1992). Anhedonia: exclusion from the pleasure dome. BMJ305, 134.

Snaith, R. P. (1993). Anhedonia: a neglected symptom of psychopathology. Psychol. Med. 23, 957-966.

Snaith, R. P., Hamilton, M., Morley, S., Humayan, A., Hargreaves, D., and Trigwell, P. (1995). A scale for the assessment of hedonic tone: the Snaith-Hamilton Pleasure Scale. Br. J. Psychiatry 167, 99-103.
Spiga, S., Lintas, A., Migliore, M., and Diana, M. (2010). Altered architecture and functional consequences of the mesolimbic dopamine system in cannabis dependence. Addict. Biol. 15, 266-276.

Stahl, S. M., Pradko, J. F., Haight, B. R., Modell, J. G., Rockett, C. B., and Learned-Coughlin, S. (2004). A review of the neuropharmacology of bupropion, a dual norepinephrine and dopamine reuptake inhibitor. Prim. Care Companion J. Clin. Psychiatry 6, 159-166.

Stevens, A., Schwarz, J., Schwarz, B., Ruf, I., Kolter, T., and Czekalla, J. (2002). Implicit and explicit learning in schizophrenics treated with olanzapine and with classic neuroleptics. Psychopharmacology (Berl.) 160, 299-306.

Sullivan, J. T., Sykora, K., Schneiderman, J., Naranjo, C. A., and Sellers, E. M. (1989). Assessment of alcohol withdrawal: the revised clinical institute withdrawal assessment for alcohol scale (CIWA-Ar). Br. J. Addict. 84, 1353-1357.

Surmeier, D. J., Ding, J., Day, M., Wang, Z., and Shen, W. (2007). D1 and D2 dopamine-receptor modulation of striatal glutamatergic signaling in striatal medium spiny neurons. Trends Neurosci. 30, 228-235.

Tempesta, E., Janiri, L., and Pirrongelli, C. (1985). Stereospecific effects of acetylcarnitine on the spontaneous activity of brainstem neurones and their responses to acetylcholine and serotonin. Neuropharmacology 24, 43-50.

Tollefson, G. D., and Sanger, T. M. (1997). Negative symptoms: a path analytic approach to a double-blind, placeboand haloperidol-controlled clinical trial with olanzapine. Am. J. Psychiatry $154,466-474$.

Tomarken, A. J., Dichter, G. S., Freid, C., Addington, S., and Shelton, R. C. (2004).
Assessing the effects of bupropion SR on mood dimensions of depression. J. Affect. Disord. 78, 235-241.

Treadway, M. T., and Zald, D. H. (2010). Reconsidering anhedonia in depression: lessons from translational neuroscience. Neurosci. Biobehav. Rev. 35 537-555.

Villa, R. F., and Gorini,A. (1991). Action of L-acetylcarnitine on different cerebral mitochondrial populations from hippocampus and striatum during aging. Neurochem. Res. 16, 1125-1132.

Volkow, N. D., Fowler, J. S., Wang, G. J., and Goldstein, R. Z. (2002). Role of dopamine, the frontal cortex and memory circuits in drug addiction: insight from imaging studies. Neurobiol. Learn. Mem. 78, 610-624.

Volkow, N. D., Wang, G. J., Fowler, J. S., Logan, J., Gatley, S. J., Hitzemann, R., Chen, A. D., Dewey, S. L., and Pappas, N. (1997). Decreased striatal dopaminergic responsiveness in detoxified cocaine-dependent subjects. Nature 386, 830-833.

Volkow, N. D., Wang, G. J., Fowler, J. S., Logan, J., Hitzemann, R., Ding, Y. S., Pappas, N., Shea, C., and Piscani, K. (1996). Decreases in dopamine receptors but not in dopamine transporters in alcoholics. Alcohol. Clin. Exp. Res. 20, 1594-1598.

White, H. L., and Scates, P. W. (1990). Acetyl-L-carnitine as a precursor of acetylcholine. Neurochem. Res. 15, 597-601.

Willner,P. (1995)."Dopaminergic mechanism in depression and mania," in Psychopharmacology: The Fourth Generation of Progress, eds F. E. Bloom and D. J. Kupfer (New York: Raven Press), 921-931.

Willner, P. (1997). Validity, reliability and utility of the chronic mild stress model of depression: a 10-year review and evaluation. Psychopharmacology 134, 319-329.
Willner, P., Hale, A. S., and Argyropoulos, S. (2005). Dopaminergic mechanism of antidepressant action in depressed patients. J. Affect. Disord. 86, 37-45.

Wise, R.A. (1982). Neuroleptics and operant behaviour: the anhedonia hypothesis. Behav. Brain Sci. 5, 39-88.

World Health Organisation. (1978). Mental Disorders: Glossary and Guide to Their Classification with the Ninth Revision of the International Classification of Diseases. Genève: WHO.

Yang, Y. K., Yeh, T. L., Yao, W. J., Lee, I. H., Chen, P. S., Chiu, N. T., and Lu, R. B. (2008). Greater availability of dopamine transporters in patients with major depression - a dual-isotope SPECT study. Psychiatry Res. 162, 230-235.

Conflict of Interest Statement: The authors declare that the research was conducted in the absence of any commercial or financial relationships that could be construed as a potential conflict of interest.

Received: 12 December 2010; accepted: 26 February 2011; published online: 17 March 2011.

Citation: Hatzigiakoumis DS, Martinotti G, Di Giannantonio Mand Janiri L (2011) Anhedonia and substance dependence: clinical correlates and treatment options. Front. Psychiatry 2:10. doi: 10.3389/ fpsyt.2011.00010

This article was submitted to Frontiers in Addictive Disorders, a specialty of Frontiers in Psychiatry.

Copyright (c) 2011 Hatzigiakoumis, Martinotti, Di Giannantonio and Janiri. This is an open-access article subject to an exclusive license agreement between the authors and Frontiers Media SA, which permits unrestricted use, distribution, and reproduction in any medium, provided the original authors and source are credited. 